\title{
Editorial
}

\section{A Prize as a Salutation}

My first encounter with Professor William Bynum was in 1998, as I waited with much nervousness in the corridors outside the lecture theatre at the Wellcome Institute for the History of Medicine. A greeting and encouragement, both provided in a booming voice, was just what a young research fellow, keen to impress in what was widely regarded as a mecca of learning, required. My seminar was completed without incident, thanks in great part to the self-belief that this generous stranger had been able to impart in a matter of minutes. Some years later, I was offered a lectureship at the newly formed Wellcome Trust Centre for the History of Medicine at University College London (WTCHOM). I joined up with great excitement, as it offered me the opportunity to work with a number of renowned scholars; I also looked forward to getting to know Bill better and was keen to learn new skills from him. I was not to be disappointed. Despite not being formally chosen to be my academic mentor, and being busy with a variety of projects, Bill was always generous with his time and academic links, ensuring that he was around to help his young colleagues settle quickly and easily. The WTCHOM was, in 2001, blessed by visits by brilliant scholars from all over the world, by easy access to the splendid Wellcome Library and Archives, and by incredibly generous levels of support for research and teaching provided by the Wellcome Trust. It was an easy place to get overawed by; Bill's good-humoured mentoring ensured that this did not happen to the Centre's intake of lecturers, research fellows and doctoral students. His support enabled - indeed, empowered - young scholars to ask probing questions of the existing historiography and actively push disciplinary boundaries.

Bill was plain speaking and did not have much time for pretentious academics, whose sensibilities were often the most brittle in the face of incisive and honest feedback. But, as an observer with a prime ringside view, I marvelled at the depth of Bill's scholarship as he posited numerous questions after the many academic presentations organised at the WTCHOM. There was something magnificent about the man - he would always seek to end his barrage of enquiry with something positive, providing even the most inexperienced and hapless presenters with cause to remain enthusiastic about their chosen research. It became very apparent, in my ten years at the WTCHOM, that this generosity with his knowledge, time and comradeship had won Bill legions of admirers and friends the world over. There was, of course, so much more to admire about him. Bill's deep knowledge about sports, food cultures and the arts, his wit and good humour, and his innate decency armed him with an invaluable gift him to steer discussions in new directions, which frequently helped dissipate tensions that can envelop any working environment. His deep-seated belief in the need to promote democracy, open-minded debate and cultural sensitivity in the work-place - traits that can be directly linked to his deep love of books and a never-ending search for new knowledge - have been passed on to several generations of scholars, and are a constant reminder to all of us about the importance of the academic mission. All these traits also made him a most effective negotiator, which explains how he was able to mobilise support from within the Wellcome Trust and University College 
London as he oversaw a dramatic expansion of the Wellcome Institute of the History of Medicine.

Many of us feel blessed to have known Bill; Professor Andrew Scull's essay accompanying this editorial is a wonderful testimony to Bill's many contributions to the history of medicine and its related sciences. I am, therefore, delighted to take this opportunity to announce the launch of the William Bynum Prize this year, which is made possible by the generosity of Cambridge University Press. That Cambridge University Press has decided to participate in honouring Bill in this way is fitting considering that it published the seminal Science and the Practice of Medicine in the Nineteenth Century in 1994 (an academic partnership that continued over the years). Cambridge University Press's support for the William Bynum Prize is also testament to its commitment to supporting young scholars of the history of medicine, a cause that has always been dear to Bill's heart.

The William Bynum Prize will be awarded to the author of an original essay on any theme relating to the history of medicine and its related sciences, and the competition will be open to doctoral students and early post-doctoral researchers (that is, candidates in the first three years of their post-doctoral career at the point of submission of their entry). The awarding committee will be chaired by Professor Bynum himself and he will be supported by the journal's editors and members of the editorial advisory board, who will be invited to provide their expert opinion on specific cases. Submissions - and all enquiries about entering the competition - should be directed to the journal editor by the 1 September 2013. The details of the winning essay and its author will be announced in the first issue of 2014. The William Bynum Prize will take the shape of a $£ 250$ cash award and $£ 250$ in Cambridge University Press vouchers. The winning entry will be published in Medical History if it succeeds in undergoing the usual, rigorous reviewing processes.

\section{SANJOY BHATTACHARYA}

Director, Centre for Global Health

Histories, Department of History,

University of York, Heslington Campus,

York YO10 5DD, UK.

Email: sanjoy.bhattacharya@york.ac.uk 